\title{
members only encodes a Drosophila nucleoporin required for Rel protein import and immune response activation
}

\author{
Anne E. Uv, ${ }^{1}$ Peggy Roth,${ }^{1}$ Nikos Xylourgidis, ${ }^{1}$ Anna Wickberg, ${ }^{1}$ Rafael Cantera, ${ }^{2}$ \\ and Christos Samakovlis ${ }^{1,3}$ \\ ${ }^{1}$ Umeå Center for Molecular Pathogenesis (UCMP), Umeå University, S-90187 Umeå, Sweden; ${ }^{2}$ Department of Zoology, \\ Stockholm University, S-10691 Stockholm, Sweden
}

\begin{abstract}
Many developmental and physiological responses rely on the selective translocation of transcriptional regulators in and out of the nucleus through the nuclear pores. Here we describe the Drosophila gene members only (mbo) encoding a nucleoporin homologous to the mammalian Nup88. The phenotypes of mbo mutants and mbo expression during development are cell specific, indicating that the nuclear import capacity of cells is differentially regulated. Using inducible assays for nucleocytoplasmic trafficking we show that mRNA export and classic NLS-mediated protein import are unaffected in mbo mutants. Instead, mbo is selectively required for the nuclear import of the yeast transcription factor GAL4 in a subset of the larval tissues. We have identified the first endogenous targets of the mbo nuclear import pathway in the Rel proteins Dorsal and Dif. In mbo mutants the upstream signaling events leading to the degradation of the IKB homolog Cactus are functional, but Dorsal and Dif remain cytoplasmic and the larval immune response is not activated in response to infection. Our results demonstrate that distinct nuclear import events require different nucleoporins in vivo and suggest a regulatory role for $\mathbf{m b o}$ in signal transduction.
\end{abstract}

[Key Words: Nuclear import; Rel family; Nup88; innate immunity; tracheal branch fusion]

Received January 21, 2000; revised version accepted June 5, 2000.

Many developmental and physiological responses rely on signal transduction pathways that culminate with the selective nuclear import or export of gene regulatory proteins. Thus, the segregation of cellular activities into nuclear and cytoplasmic compartments constitutes an important level of gene regulation (Kaffman and O'Shea 1999). One example is the activation of innate immune responses in mammals and flies, which depend largely on the induced translocation of NF- $\mathrm{kB} / \mathrm{Rel}$ proteins from the cytoplasm to the nucleus (Hoffmann et al. 1999). Rel proteins are held in the cytoplasm in an inactive state by interaction with an inhibitor protein, IкB, and upon signaling the I $\mathrm{B}$ protein becomes phosphorylated and degraded, allowing the nuclear import of NF- $\mathrm{B}$ (Mercurio and Manning 1999). Despite the well-defined signaling pathways that lead to the dissociation of the NF-кB proteins from their cytoplasmic anchoring inhibitors, little is known about the molecules that mediate their actual translocation across the nuclear envelope.

All trafficking of macromolecules between the cytoplasm and the nucleus, including regulated and general import and export of RNAs and proteins, occurs through

${ }^{3}$ Corresponding author.

E-MAIL christos@ucmp.umu.se; FAX 46-(0)90-778007. nuclear pore complexes (NPCs). Transport through NPCs requires soluble import and export receptors. Nuclear protein import commences in the cytoplasm by the interaction between the cargo protein and its import receptor, typically through the nuclear localization signal (NLS), a short stretch of basic amino acids responsible for nuclear targeting. The transport receptor then docks the complex to the nuclear pore and escorts the cargo through the pore. Upon reaching the nucleoplasm, the cargo-transporter complex is dissociated and the transporter returns to the cytoplasm for a new round of import. A large family of related proteins can form soluble transport receptors for different types of cargoes through the NPCs. Importin- $\beta$, for example, acts together with importin- $\alpha$ in the import of proteins that harbor a bipartite NLS or a classic NLS such as that of SV40 large T antigen. Importin- $\beta$ can also dimerize with other members of the importin family and recognize different NLSs (Görlich and Kutay 1999). The presence of distinct transporters between the cytoplasm and the nucleus raises questions on how the diversity of transporter-cargo complexes is accommodated at the level of the nuclear pore machinery. More than 1 million macromolecules may pass through the nuclear envelope of a eukaryotic cell per minute, and an important challenge is to understand how the NPCs accommodate both effi- 
cient basal bidirectional trafficking and rapid translocation of regulatory proteins upon signaling. In higher eukaryotes each NPC has a mass of $125 \mathrm{MD}$ and contains 50-100 different proteins. Some of these have been mapped to distinct parts of the NPC and have been shown to interact with transport receptors (Shah and Forbes 1998). It is unclear, however, if different nucleoporins participate in distinct protein import events leading to regulatory changes of gene expression in vivo or if they are structural components of an elaborate channel for general nuclear entry.

We have identified a Drosophila gene, members only $(\mathrm{mbo})$, that encodes a novel nucleoporin homologous to the mammalian Nup88 (Bastos et al. 1997; Fornerod et al. 1997). mbo is selectively required for the nuclear import of the Rel family transcription factors Dorsal and Dif and the activation of an immune response. The zygotic expression and phenotypes of $m b o$ during organogenesis are tissue specific, suggesting that the nuclear import capacities of different cells may be regulated. Our results suggest that individual nucleoporins are required for distinct nuclear protein import pathways and provide an example of substrate specificity within the NPC with important implications for the selective import of transcriptional regulators upon signaling.

\section{Results}

mbo encodes a Drosophila homolog of the human nucleoporin Nup88

The enhancer trap insertion 1(3)5043 was identified in a screen for P-element strains that express the $1 a c Z$ marker in distinct subsets of cells of the Drosophila tracheal (respiratory) system. We have cloned the gene disrupted in this mutant strain by isolating a $6-\mathrm{kb}$ genomic fragment flanking the transposon insertion and named the gene $(\mathrm{mbo})$ due to its selective function in nucleocytoplasmic transport (see below). A 1.1-kb fragment isolated from a P1 clone that spans the genomic region (Fig. 1B), identified a single mRNA species of $\sim 2.5 \mathrm{~kb}$ by Northern blot hybridizations (data not shown), and was subsequently used as a probe to isolate cDNA clones from an embryonic cDNA library. The longest cDNA was $2.5 \mathrm{~kb}$ long and sequence analysis identified a predicted ORF of 702 residues. Database searches for proteins related to the deduced amino acid sequence revealed that it represents a novel protein with homology to a human and a rat NPC protein, called Nup88 (Fig. 1A). The predicted sequences of the fly and the human Nup 88 proteins are $25 \%$ identical and share $44 \%$ homology that extends throughout their lengths; therefore, we refer to the fly protein as Drosophila Nup88 (Dnup88). The most striking feature of the Dnup88 sequence is that its carboxy-terminal region is predicted to form a coiledcoil structure (Fig. 1A). Such structures are often found to mediate protein interactions, and for human Nup88, this region is important for its association with the NPC (Bastos et al. 1997).

To investigate if the sequence similarity between
Dnup88 and its mammalian homolog represents conservation of their function, we addressed the subcellular localization of Dnup88. We generated a polyclonal antiserum against the Dnup88 protein and tested its specificity on Western blots of embryonic and larval extracts (Fig. 1C). A protein of $\sim 90 \mathrm{kD}$ is detected in wild-type embryos and larval CNS with this antiserum and is absent in mbo mutant CNS (see below). In addition, the level of the protein recognized by the antiserum is strongly increased in CNS from larvae that overexpress Dnup88 from an $m b o$ transgene under the control of the hsp70 promoter. When used to stain embryos, this antiserum produces a pronounced ring-like staining that coincides with the nuclear envelope revealed by staining with antibodies against nuclear lamin (Fig. 1D). In confocal optical sections, the Dnup88 staining appears punctuated along the nuclear envelope, indicating that Dnup88 localizes specifically to the NPCs. Thus, Dnup88, like vertebrate Nup88, appears to be a component of the NPC. When human Nup88 is overexpressed in cultured cells, the protein becomes localized in the cytoplasm but not in the nucleus (Bastos et al. 1997). Similarly, in embryos that overexpress Dnup88 the protein is excluded from the nucleus (data not shown), suggesting that it is normally localized on the cytoplasmic side of the nuclear envelope.

\section{Cell-specific expression and functions of mbo in development}

Homozygous embryos from the 1(3)5043 P-element strain show sporadic but distinct defects in the connecting branches of the tracheal network (Samakovlis et al. 1996b). In this strain the transposon is inserted into the 5 '-untranslated part of mbo (Fig. 1B), causing pupal lethality in homozygous animals. To investigate the function of $m b o$ in the trachea we generated and characterized revertants and strong loss-of-function P-element excision mutants. Several of the strains established were homozygous viable, and five strains, including $m b o-1$ and mbo-2, were homozygous lethal and failed to complement each other, the original P-element mutation and a chromosomal deletion for the region. Using cDNA fragments from the mbo cDNA as probes on genomic Southern blots we identified the molecular lesions of the excision alleles. Part of the nucleoporin-coding region is deleted in $m b o-2$ and almost the entire coding region is deleted in $m b o-1$ (Fig. 1B). The $m b o$ excision mutants fail to pupariate and finally die as third instar larvae after a prolonged (up to 1 week) period of larval life. To confirm that the lethality in mbo mutants is due to disruption of the $m b o$ gene only, we rescued this phenotype by expressing the full-length mbo cDNA in $m b o-1$ and $m b o-2$ mutants throughout development under the control of a heat shock promoter.

During embryogenesis, 100 of the $\sim 1600$ cells of the tracheal epithelium mediate the connection of 20 individual metameres to a network that facilitates respiration during larval life (Samakovlis et al. 1996a). Every branch fusion event involves two cells, each located at 
B

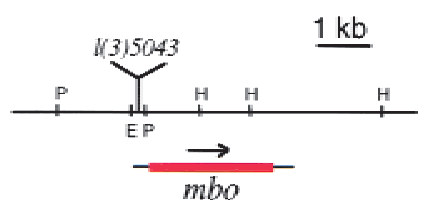

mbor

$m b o-2$

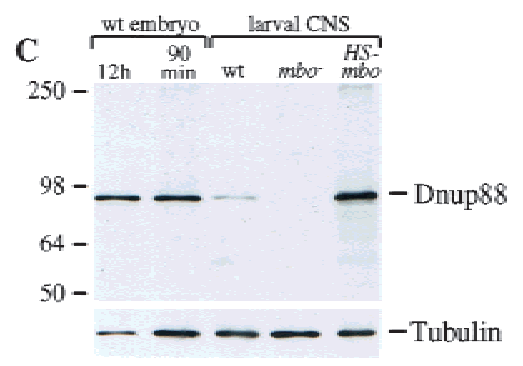

D

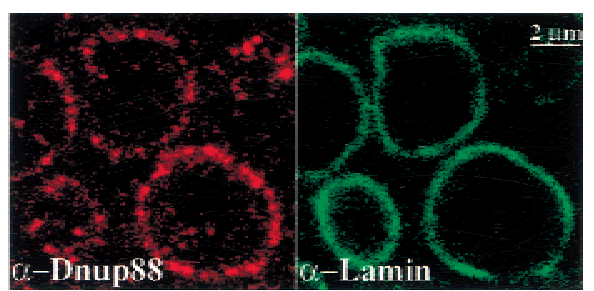

Figure 1. The mbo product is homologous to the human nucleoporin Nup88. (A) The predicted amino acid sequence of Dnup88 (top) is aligned with human Nup88 (bottom). Identities are indicated by bars, and homologies by dots. The carboxy-terminal regions predicted to form a coiled-coil structure are shaded. Numbers indicate the positions of the respective amino acid residues. $(B)$ Restriction map of the mbo locus (top horizontal line) for EcoRI (E), HindIII (H), and PvuII (P), showing the site of P-element insertion in 1(3)5043 relative to the mbo transcript (the ORF is marked with red; the arrow shows the direction of transcription). The 1.1-kb EcoRI-HindIII fragment spanning the P-element insertion was used to screen cDNA libraries. The extent of deletions in the $m b o-1$ and mbo-2 alleles is depicted as gaps. (C) Western blot of extracts from 0- to-12 hr-old embryos, 0- to 90-min-old embryos, wild-type larval CNS, mbo mutant CNS, and CNSs from larvae that overexpress Dnup 88 from an $h s p 70-m b o$ transgene probed with antiserum against the carboxy-terminal part of Dnup88. Staining for $\beta$-tubulin provides a loading control (bottom). (D) Confocal section of wild-type embryonic epidermis at stage 15 showing colocalization of Dnup88 (anti-Dnup88, red, left) with lamin (anti-lamin, green, right).

the tip of the fusing branches. The fusion cells extend elaborate cytoplasmic processes, form an intracellular lumen, contact each other, and finally form a continuous bicellular anastomosis connecting the two branches (Samakovlis et al. 1996b). These cells selectively express a set of fusion marker genes, including 1(3)5043 (mbolacZ) (Fig. 2A,B). In mbo-1 embryos $20 \%(n=480)$ of the dorsal anastomoses failed to form (Fig. $2 \mathrm{E}, \mathrm{K}$ ), and in $\mathrm{mbo}$ larvae the dorsal branches remained unconnected (Fig. $2 \mathrm{~F}, \mathrm{~L})$. The rest of the trachea, including the terminal branches that derive from cells not expressing the mbolacZ marker and grow parallel to the fusion sprouts, were unaffected in mbo mutants (Fig. 2F,L). In addition, the expression of the early fusion cell marker esg-lacZ and other tracheal cell-specific markers was not altered in mbo mutant embryos, suggesting that $m b o$ is required in the fusion cells subsequent to their cell fate specification (Fig. 2 G,M). The fusion cells have another important role in mediating the breakage and release of old tracheal cuticle at each larval molt (Manning and Krasnow 1993). The mbo-lacZ marker is expressed in the fusion cells throughout larval life, and all mbo larvae showed discontinuities in the tracheal cuticle in positions corresponding to the fusion junctions of the dorsal trunks (Fig. 2H,N). Thus, the cell-specific zygotic expression of $m b o-l a c Z$ in the trachea reflects cell-specific requirements in the fusion cells. In the embryo, mbo-lac $Z$ expression is also prominent in a subset of the cells of the developing CNS, in dynamic stripes of epidermal cells, in the lymph glands, and in the intestinal tract including the proventriculus and foregut (data not shown). Because of the abundant distribution of maternally derived gene products during embryogenesis, however, we were unable to detect significant differences in the abundance of RNA or protein in these tissues.

In the larva, $m b o-l a c Z$ is expressed in the fat body, the trachea, the CNS, and the imaginal tissues (data not shown). Abundant mbo RNA expression can be detected in the proliferating parts of the larval nerve cord, in the optic lobes of the brain, and in the imaginal disks (Fig. 2C). Accordingly, the size of the CNS and imaginal disks of third instar mbo mutant larvae is severely reduced 


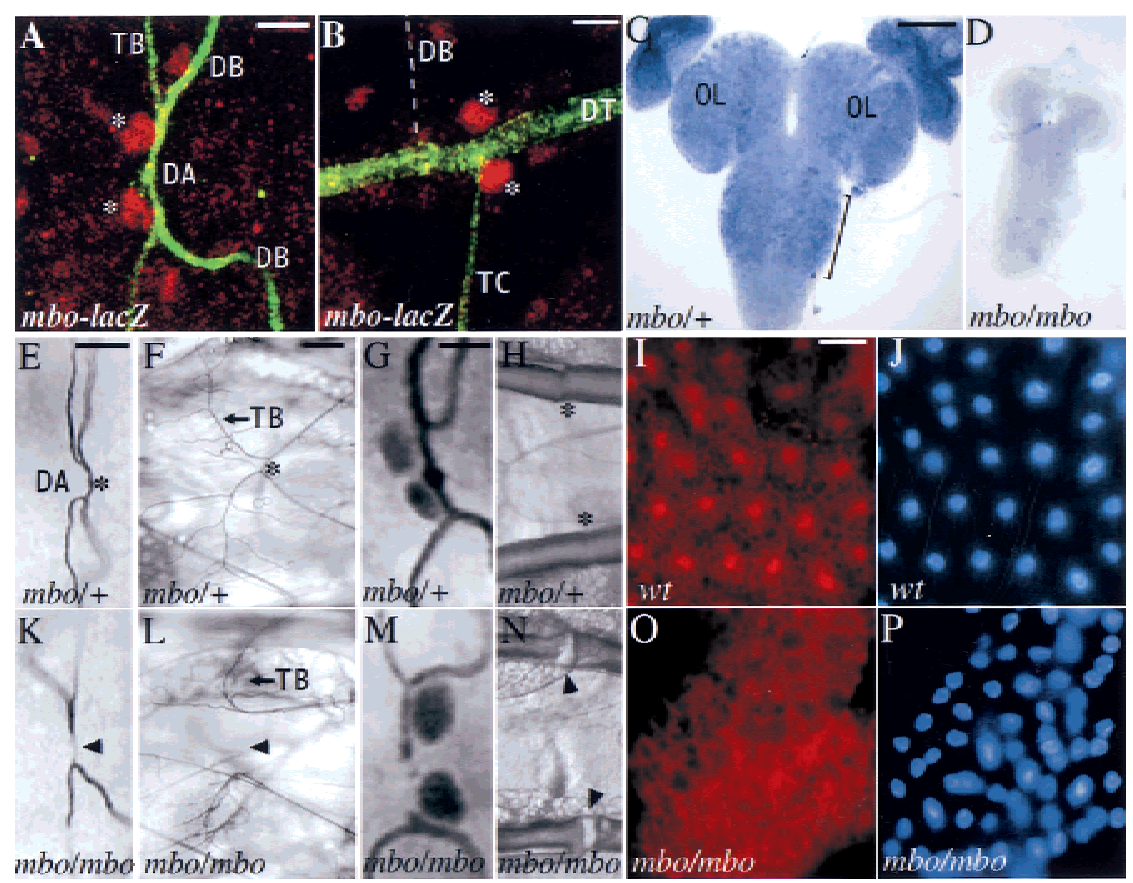

Figure 2. The expression and phenotypes of $m b o$ are cell-specific. $(A, B)$ Confocal images of a stage-16 embryo carrying one copy of the mbo-lacZ reporter stained with anti- $\beta$-galactosidase (red) and $\mathrm{mAb}$ $2 \mathrm{~A} 12$ to visualize the tracheal lumen (green). (A) lac $Z$ expression is detected in fusion cells (asterisks) of the dorsal branches (DB) forming the dorsal anastomosis (DA). mbo-lac Z is not expressed in the stalk cells of the DB or the cells extending terminal branches (TB). (B) mbo-lacZ is expressed in the fusion cells (asterisks) of the dorsal trunk (DT) but not in the stalk cells of the DB or in the transverse connective (TC). The DB is out of focus; its position is drawn with a broken line. Bars, 5 $\mu \mathrm{m}(A) ; 2 \mu \mathrm{m}(B) .(C, D)$ In situ hybridization to mbo mRNA in third instar larval CNS. In wild type $(C) \mathrm{mbo}$ is expressed in proliferating cells of the nerve cord (brackets), in the optic lobes (OL) of the brain, and the imaginal discs shown attached to the lobes. mbo RNA is not detectable in the CNS of mbo mutants $(D)$, and the size of the CNS is reduced. Bars in $C$ and $D ; 100$ $\mathrm{mm} .(E, K)$ Dorsal anastomoses in late stage-16 wild-type (asterisk in $E$ ) and mbo mutant $(K)$ embryos. In $m b o$ mutant embryos, $20 \%$ of the dorsal branches fail to connect (arrowhead in $K)$ Bar, $10 \mu \mathrm{m} .(F, L)$ Dorsal anastomoses in third instar wild-type (asterisk in $F$ ) and mbo mutant $(L)$ larvae. In mutants the DBs are disconnected (arrowhead), but terminal branching is not affected (arrows in $F, L$ ). Bar, $50 \mu \mathrm{m} .(G, M)$ Dorsal anastomoses in stage-16 embryos carrying one copy of the esg-lacZ marker. esg-lacZ is expressed in the fusion cells of both wild type $(G)$ and $m b o$ mutants $(M)$. Bars in $G$ and $M, 2 \mu \mathrm{m}$. $(H, N)$ Segments of the dorsal trunks of wild-type and $m b o$ third instar larvae. In mutants the cuticular lining of the dorsal trunks is disrupted at the positions of the fusion junctions (arrowheads in $N)$ compared to junctions in the wild type (asterisks in $H)$. Bar, $50 \mu \mathrm{m}(I-P)$ Dnup88 expression in larval fat body detected with the antiserum against the amino-terminal part of the protein. Nuclear staining is detected in wild-type larvae $(I)$ but absent in $m b o$ mutants $(O)$. The nuclei are visualized by DAPI staining in the adjacent panels $J$ and $P$. Bar in $I, J, O$, and $P, 40 \mu \mathrm{m}$.

(Fig. 2C,D). Because the antiserum against the carboxyterminal part of Dnup88 was not sensitive enough to detect the protein by in situ staining in larvae, we have generated a second rabbit antiserum against the aminoterminal part of Dnup88 and used it to describe the distribution of larval Dnup88. The specificity of the antiserum was first tested on Western blots, and it recognizes a band corresponding to Dnup88 in extracts from wildtype larvae that is absent in extracts from mbo mutants (not shown). In situ staining of wild-type larvae with this antiserum showed that the distribution of larval Dnup88 is tissue specific. Nuclear Dnup88 staining could be detected in the fat body, trachea, CNS, and imaginal disks but not in the epidermis, muscles, and gut. This tissuespecific staining was absent in mbo mutant larvae (Fig. 2I,O).

The mbo gene product is maternally provided, as early embryos (0-90 min after egg laying) contain both mbo mRNA and protein (Fig. 1C; data not shown). To study the embryonic function of mbo in animals devoid of the maternal product, we attempted to generate embryos from $m b o$ homozygous germ-line clones. Such germ-line clones were, however, unable to produce eggs; and dissection of mosaic ovaries followed by DAPI staining revealed an early mbo function in oogenesis, as mutant ovarioles did not form an oocyte. In addition, eggs from mothers homozygous for two hypomorphic mbo alleles contained an increased amount of dorsal appendage material, resembling the mutant phenotypes of genes involved in determining the dorsoventral polarity of the oocyte (data not shown). Because of the difficulty in generating embryos lacking maternal Dnup88, we focused our functional analysis on early third instar larvae that lack the zygotic mbo gene product and contain only small residual amounts of maternal Dnup88.

\section{mbo is not required for mRNA export}

Several nucleoporins identified previously have been implicated in maintaining the structural integrity of the NPC or mediating RNA export from the nucleus (Doye and Hurt 1995). To address whether Dnup88 has a function in maintaining the structural integrity of the NPCs and the nuclear envelope, we examined nuclear morphology in several tissues of mbo larvae by transmission electron microscopy. We could not detect any abnormalities in the nuclear envelope or clustering of its NPCs, as it has been described for several nucleoporin mutants in yeast. In addition, the structure of individual pores in mbo larvae (Fig. 3G) was indistinguishable from the structure of wild-type NPCs (data not shown), sug- 
gesting that $m b o$ is not required for the gross organization of the NPC or the integrity of the nuclear envelope.

To test for defects in mRNA export in mbo mutants, we used two approaches. First, we ectopically expressed Headcase (Hdc), a cytoplasmic protein that is selectively expressed in the larval imaginal tissues (Weaver and White 1995), from a heat shock promoter to test whether mbo larvae can export and translate $h d c$ mRNA from the transgene. mbo mutants and control heterozygous siblings were heat treated in the same way and were found to express similar levels of ectopic Hdc protein revealed by immunostaining (Fig. 3D-F), suggesting that RNA export is functional in mbo mutants. In yeast (Saavedra et

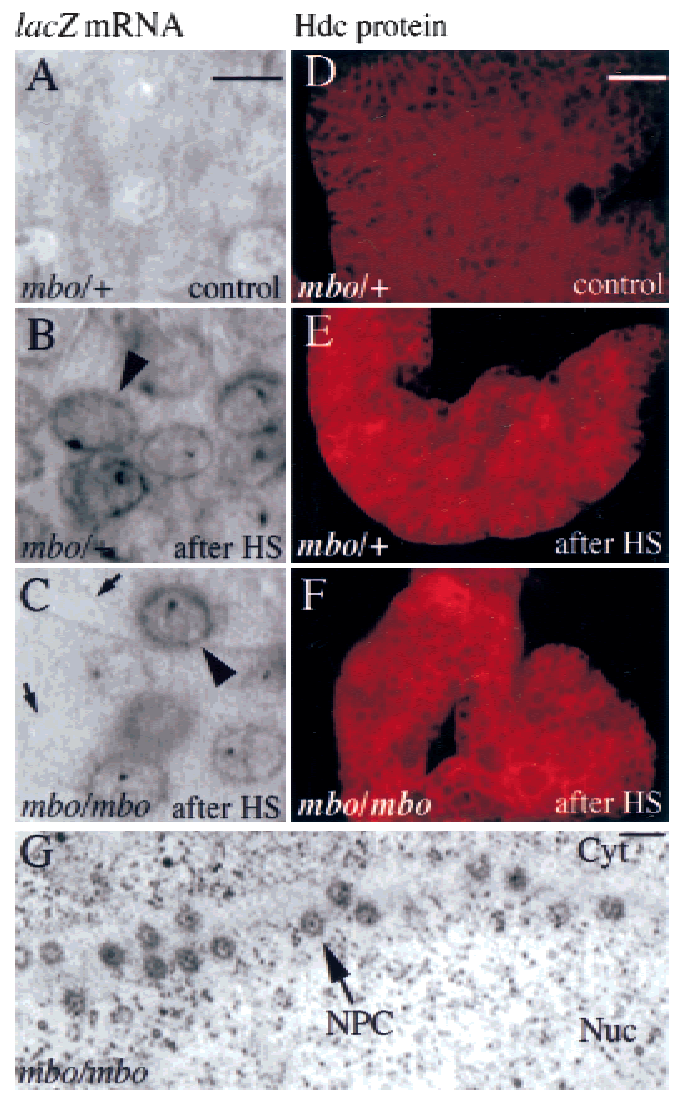

Figure 3. $m b o$ is not required for mRNA export. $(A-C)$ In situ hybridization to lacZ RNA in wild-type and $m b o$ larvae carrying the hs-GAL4 and UAS-lacZNLS transgenes. The lacZ RNA is detected in the proventriculus of wild-type $(B)$ and $\mathrm{mbo}$ mutant $(C)$ larvae after heat shock and does not accumulate in the nucleus (arrowheads). The dark spot inside each nucleus is likely to correlate with the site of transcription. lac $Z$ expression is reduced in some of the cells of mbo mutants (arrows). Bar, 10 $\mu \mathrm{m}$. $(D-F)$ Heat shock-induced expression of Hdc protein in wild-type and mbo mutants. Fat bodies from untreated wildtype $(D)$ and heat-shocked wild-type $(E)$ and $m b o(F)$ larvae carrying the $h s-h d c$ transgene were stained with an antibody against the Hdc protein. Bar, $50 \mu \mathrm{m}$. (G) Electron micrograph of a section through the lymph gland of an mbo larva. In this tangential section, several NPCs (arrow) can be identified in the space between the cytoplasm (Cyt) and the nucleus (Nuc). Their distribution and morphology are indistinguishable from wild type at this level. Bar, $100 \mathrm{~nm}$. al. 1997) and in Drosophila (data not shown) heat shock treatment causes a transient block of general poly(A) RNA export. Because the $h d c$ transgene carries the $3^{\prime}$ UTR of $h s p 70$ and there is evidence for a different export pathway for heat-shocked mRNA in yeast (Saavedra et al. 1997), we also examined the export of an mRNA that does not carry any sequences derived from hsp 70. Thus, instead of analyzing the export of RNAs directly controlled by the $h s p 70$ promoter, we studied the export of de novo-expressed UAS-lacZ RNA activated by the inducible expression of a hs-GAL4 driver in mutant and wild-type larvae. The RNA was detected $4 \mathrm{hr}$ after heat treatment by in situ hybridizations with a probe against lacZ. We have analyzed several tissues, including the proventriculus, lymph glands, trachea, and epidermis and were not able to observe any nuclear accumulation of lacZ RNA in mbo mutants (Fig. 3A-C; data not shown). Thus, general mRNA export and heat-shocked mRNA export remain unaffected in mbo mutants. In the same experiments we noticed that although the localization of lacZ mRNA was not affected in mbo mutants, its relative amount produced by different tissues was reduced. This observation suggested that the nuclear import of the transcription factor(s) required for the activation of the UAS-lacZ transgene might be affected in the mutants.

mbo mutants are defective in the nuclear import of a subset of proteins

We first asked whether general nuclear protein import is reduced in mbo larvae. Instead of assaying for accumulation of endogenous nuclear proteins in the cytoplasm, we studied de novo translocation of transcription factors that were expressed under the control of the inducible hsp70 promoter. In this way we aimed to identify primary rather than secondary nuclear transport defects. Using this assay we tested the subcellular localization of Grainyhead (Grh), a Drosophila transcription factor with a predicted bipartite NLS; Antennapedia (Antp), with a predicted small basic type of NLS; and a $\beta$-galactosidase fusion protein carrying the classic type of NLS from the SV40 large $\mathrm{T}$ antigen. The localization of each protein was determined by immunostaining $2 \mathrm{hr}$ after heat shock and was compared in tissues that lack endogenous Grh and Antp proteins, mainly the fat body, lymph glands, and proventriculus. All three proteins tested were nuclear in these tissues in both $m b o$ and wild-type larvae after heat shock (Fig. 4A-I). They were also nuclear in all the other tissues in which they are normally expressed (data not shown). Because the three nuclear proteins we assayed are of different sizes and harbor different types of NLSs, we conclude that $m b o$ mutants are not generally defective in nuclear protein import nor do they appear impaired in their transcriptional and translational abilities.

The reduced expression levels of the UAS-lacZ transgene in a subset of tissues in mbo larvae suggested that GAL4 nuclear entry may be affected in the mutants. The yeast transcription factor GAL4 is constitutively 
Figure 4. $m b o$ is not required for general protein import. $\beta$-Gal-NLS, GRH, Antp, and GAL4 were expressed ectopically in wild type and mbo mutants and detected with the relevant antibodies. GRH, Antp, and GAL4 were expressed under the control of the hsp 70 promoter, and $\beta$-Gal-NLS expression was activated by heat shock-induced GAL4 protein. $(A, D, G, J)$ Background levels in wild-type fat bodies of untreated animals. Nuclei are visualized by DAPI in the adjacent panels. $(B, E, H, K)$ In wild-type larvae all four proteins are found in the nuclei of the fat bodies after heatshock. $(C, F, I, L)$ In fat bodies of mbo mutants all proteins become nuclear except for GAL4, which is predominantly cytoplasmic $(L)$. The amount of $\beta$-Gal-NLS in $C$ is reduced compared to that in $B$. Bar, $50 \mu \mathrm{m}$.

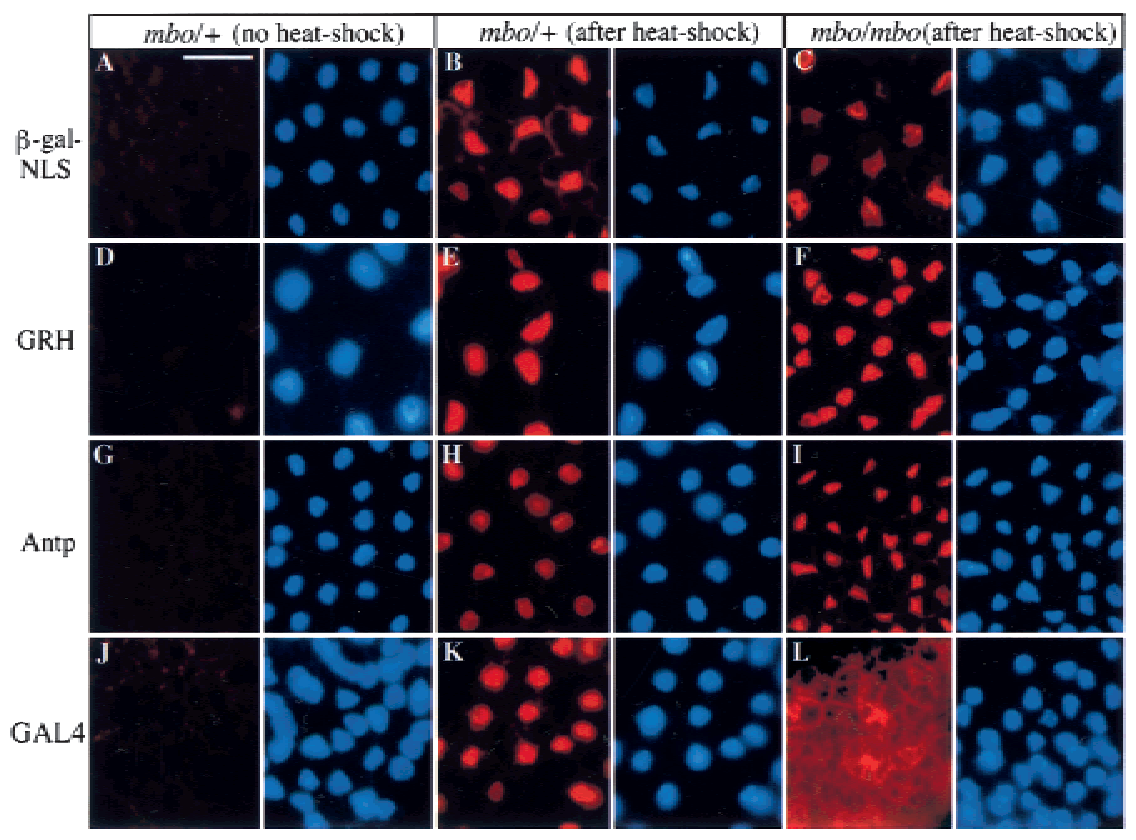

nuclear, and its nuclear targeting requires an unconventional NLS composed of the first 74 residues of the protein that is sufficient to target $\beta$-galactosidase into the nucleus (Silver et al. 1984). GAL4 was expressed in mbo and heterozygous larvae under the control of the hsp 70 promoter, and its subcellular distribution was assessed by immunostaining. GAL4 protein was nuclear in all tissues of mbo heterozygotes (Fig. $4 \mathrm{~K}$; data not shown), but its nuclear localization was impaired in mbo mutants. In the same cells in which the Grh, Antp, and NLS- $\beta$ gal proteins were nuclear, GAL4 was predominantly cytoplasmic. This defect in GAL4 nuclear accumulation was evident in the fat body (Fig. 4L), lymph gland, proventriculus, and tracheal spiracles. In the epidermis, the gut, and the primary tracheal branches of mbo mutant larvae, however, GAL4 was nuclear (Fig. 5 C,E). Accordingly, mbo larvae carrying the hsp 70 GAL4 driver and the UAS-lacZ reporter expressed lower levels of lacZ RNA in tissues where GAL4 remained cytoplasmic (Fig. 3B,C; data not shown). Thus, the defect of mbo mutants in the nuclear import of GAL4 is tissue specific.

The selective phenotype of mbo larvae in GAL4 nuclear localization may be due either to a specific requirement of mbo for GAL4 nuclear translocation or a subtle but general defect in protein import that is more easily detectable by the nuclear accumulation of GAL4. In the latter scenario yeast GAL4 would be imported at a lower rate than the endogenous fly proteins and, thus, within the 2-hr period of our assay, would be detected mainly in the cytoplasm. To address these possibilities we examined the subcellular localization of GAL4 and Grh at different times after induction in wild-type and mbo mutants. In wild-type larvae we find that both proteins are nuclear at the earliest time point that they can be detected, which is $1 \mathrm{hr}$ after heat shock (Fig. 5A,B). Thus, the kinetics of their nuclear accumulation do not appear significantly different. In addition, we never detected cytoplasmic Grh in mbo mutants even in 1-weekold third instar larvae that have been arrested in their development for a prolonged period, arguing that general nuclear import is functional in the absence of Dnup88

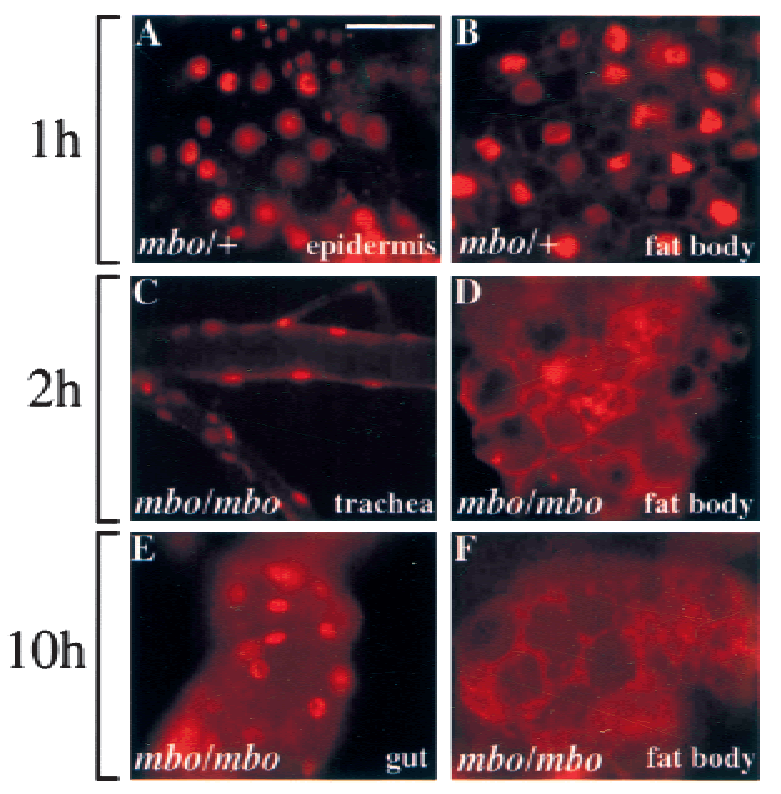

Figure 5. GAL4 nuclear import in mutant and mbo heterozygous larvae. GAL4 was expressed under the control of the $h s p 70$ promoter and detected with an anti-GAL4 antibody. $(A, B)$ One hour after heat shock treatment GAL4 is nuclear in heterozygous larvae, $(A)$ epidermis; (B) fat body]. $(C-F)$ In mbo mutants, GAL4 remains cytoplasmic in the fat body, both at 2 and $10 \mathrm{hr}$ after heat treatment $(D, F)$, whereas it is nuclear in the trachea (C; $2 \mathrm{hr}$ after heat shock) and the gut $(E ; 10 \mathrm{hr}$ after heat shock) of the same animals. 
(data not shown). We also examined the localization of GAL4 in mbo mutants at different time points after heat shock induction. The levels of nuclear GAL4 do not increase at $10 \mathrm{hr}$ after induction compared to $2 \mathrm{hr}$ (Fig. 5F). Even at $20 \mathrm{hr}$ after heat shock, when the levels of nuclear and cytoplasmic GAL4 protein become reduced, GAL4 remains cytoplasmic in the mutant larvae. These results suggest that the mbo mutant phenotype in GAL4 localization is not due to a general defect in protein import kinetics but, rather, to a selective requirement for Dnup88 in the nuclear import of a distinct class of cargo proteins, including GAL4.

mbo is required for nuclear translocation of the Rel proteins Dorsal and Dif and the activation of an immune response

To identify endogenous targets of the Dnup8 8 import pathway we also tested the translocation of Drosophila proteins that enter the nucleus upon signaling during developmental and physiological responses. We examined the nuclear localization of endogenous Extradenticle (Exd), a Drosophila homeodomain protein, whose nucleocytoplasmic distribution is dynamically regulated (Mann and Abu-Shaar 1996) and were unable to detect any differences in its subcellular localization in $m b o$ and wild-type larvae (data not shown). Similarly, the nuclear localization of phosphorylated MAP kinase (MAPK) monitored with an anti-dpERK antibody (Gabay et al. 1997) remained unaffected in mbo embryos and larvae (data not shown).

During early embryogenesis, the Drosophila NF-кB protein Dorsal is released from the IкB homolog Cactus in response to signaling from the Toll receptor and becomes nuclear on the ventral side of the embryo to activate transcription (Morisato and Anderson 1995). The same signaling cascade is part of the activation of the larval immune response in the fat body and is induced upon challenging the larvae with a bacterial infection (Lemaitre et al. 1996). We investigated the subcellular localization of Dorsal in fat bodies of homozygous $m b o$ larvae and their heterozygous siblings. Both mutant and heterozygous larvae were reared together, and in nonchallenged larvae of both genotypes Dorsal was predominantly cytoplasmic (Fig. 6A,D). When mbo heterozygous larvae were infected with a needle dipped in a bacterial culture, Dorsal became translocated into the nuclei of fat body cells within $45 \mathrm{~min}$ (Fig. 6B). In mbo mutants that received the same treatment, Dorsal remained cytoplasmic (Fig. 6E). We have also observed that Dorsal enters
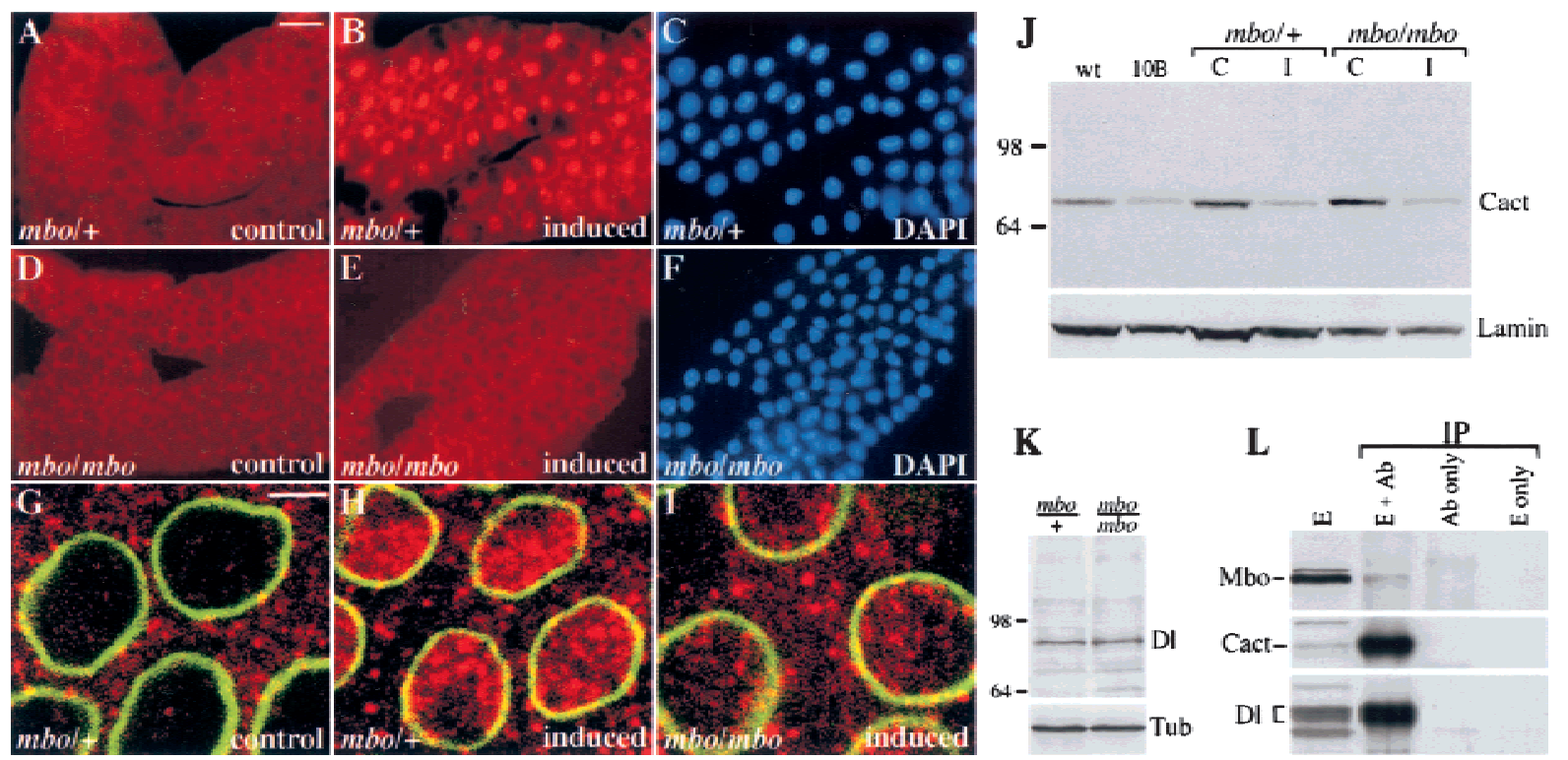

Figure 6. $m b o$ is required for nuclear translocation of Dorsal. $(A-F)$ Fat bodies from control wild-type $(A)$ and $m b o$ mutant $(D)$ larvae stained for Dorsal. One hour after bacterial infection Dorsal is predominantly nuclear in wild type $(B)$ but remains cytoplasmic in $m b o$ mutants $(E)$. Nuclei where visualized with DAPI $(C, F)$. $(G-I)$ Confocal images of lymph glands from control wild-type $(G)$, induced wild-type $(H)$, and induced mbo (I) larvae stained for lamin (green) and Dorsal (red). In mbo mutants, the inducible Dorsal translocation is reduced severely. ( $J$ ) Cactus becomes degraded in mbo mutants. Protein extracts from control (C) and infected (I) wild-type and mbo larvae and untreated Toll $10^{\mathrm{b}}$ larvae were obtained in parallel with in situ experiments, blotted, and probed with antisera against Cactus. The amount of Cactus is similarly reduced in untreated Toll $10^{\mathrm{b}}$ and induced wild-type and $\mathrm{mbo}$ larvae. The filter was probed with an anti-lamin antibody as loading control. $(K)$ The amount of Dorsal in wild-type and mbo mutant larvae is similar. Shown is a Western blot of larval extracts probed with the Dorsal antiserum followed by staining with an anti-tubulin antibody for loading control. $(L)$ Dnup88 and Dorsal coimmunoprecipitate from protein extracts of 0- to 3-hr wild-type embryos. Embryo extract (E) and precipitates produced from incubations of extract with anti-Dorsal and beads ( $\mathrm{E}+\mathrm{Ab}$ ), anti-Dorsal and beads without extract (Ab only), and extract and beads without anti-Dorsal (E only) were analyzed by Western blot. The blot was probed with antisera against Dnup88 (top), Cactus (middle) and Dorsal (bottom). 
the nuclei of the larval hematopoietic organ, the lymph gland, upon infection of wild-type animals (Fig. 6G,H). Also in this tissue, the nuclear translocation of Dorsal is severely impaired in mbo mutants (Fig. 6I).

To further assess the effect of $m b o$ on Rel protein import, we examined whether the upstream signaling events leading to Dorsal nuclear import are functional in mbo mutants. We first determined the amount of Dorsal, on Western blots of extracts from wild-type and mbo larvae using the Dorsal antiserum, and detected comparable amounts of Dorsal in larvae from both genotypes (Fig. 6K). We then asked whether Cactus is degraded upon bacterial stimulation. Wild-type and mbo larvae were treated in parallel and divided into two pools, one for in situ staining for Dorsal and the other for Cactus staining on Western blot. As a control for the procedure the amount of Cactus was analyzed in wild-type and Toll10 ${ }^{\mathrm{b}}$ larvae, bearing a dominant gain-of-function mutation of the Toll receptor (Schneider et al. 1991). In both mbo mutant and wild-type larvae the level of Cactus is reduced within $30 \mathrm{~min}$ after challenge (Fig. 6J; Nicolas et al. 1998) to similar levels found in Toll10 larvae; nuclear Dorsal however, is only detected in wild-type larvae. Thus, mbo is required downstream of the events leading to Cactus degradation.

Because the basic transport machinery across the nuclear pore appears functional in mbo mutants we anticipated that Dnup88 might participate in a protein complex that facilitates nuclear translocation of Dorsal. To investigate this possibility we carried out immunoprecipitations from protein extracts of 0- to 3-hr-old-embryos with Dorsal antiserum and attempted to detect Dorsal, Dnup88, Cactus, and an unrelated abundant nuclear protein, Adrift (Englund et al. 1999), on Western blots of the precipitate. The antibodies against Dorsal, Dnup88, and Cactus each detected a protein at the expected molecular weight range of their targets (Fig. 6L). As has been shown previously with the same antisera (Edwards et al. 1997), Cactus antibodies detect a strong signal in the Dorsal immunoprecipitate. Compared with the intensity of this band, the signal detected by the Dnup88 antiserum is weaker, indicating that the fraction of Dorsal protein found in complex with Dnup88 is smaller than the amount of Dorsal bound to Cactus. We could not detect any Adrift in these immunoprecipitates; neither could we detect Dnup88 in comparable immunoprecipitations performed with the Adrift antiserum (data not shown). Thus, Dnup88 appears to participate directly in Dorsal nuclear import.

In wild-type larvae nuclear translocation of the Rel proteins Dorsal and Dif (Ip et al. 1993), in response to a bacterial injection, is followed by the rapid transcriptional activation of genes encoding antimicrobial peptides (Hoffmann et al. 1999). We first examined whether the inducible nuclear entry of Dif might also require mbo. Like Dorsal, Dif is translocated into the fat body nuclei of mbo heterozygous larvae upon infection, and this translocation is impaired in mbo larvae (Fig. 7A-C). Accordingly, we find that a reporter construct of the inducible cecropin A promoter coupled to lacZ (cecA1lacZ; Petersen et al. 1995) is strongly induced in heterozygous larvae upon infection, whereas it is nonresponsive in mbo mutants (Fig. 7D-F). An analysis of the inducible expression of the genes for antimicrobial peptides Drosomycin and Diptericin by Northern blot hybridizations revealed that their induction is also severely impaired in mbo larvae (Fig. 7G). These results indicate that at least two of the identified fly Rel transcription

Figure 7. Nuclear import of Dif and induction of antimicrobial gene expression is impaired in $m b o$ larvae. $(A-C)$ Fat bodies from wild-type $(A, B)$ and $m b o$ mutant $(C)$ larvae stained for Dif protein. One hour after bacterial infection Dif is nuclear in wild-type fat body $(B)$ but remains cytoplasmic in mbo mutants $(C)$. $(D-F)$ Expression of cec-lacZ in fat bodies from wild-type $(D, E)$ and mbo mutant $(F)$ was revealed by staining against $\beta$-galactosidase. Two hours after bacterial challenge wild-type larvae express high levels of cec-lacZ $(E)$, whereas $m b o$ mutants do not express the reporter $(F)$. $(G)$ Northern blot analysis of the expression of drosomycin (Drom) and diptericin (Dipt) in wild-type and mbo mutant larvae. RNA samples from control (C) and induced (I) larvae from both genotypes were probed. In two of three experiments, the level of drosomycin RNA was elevated in untreated animals, but both genes were always strongly induced upon bacterial infection in wild-type larvae. This induction was severely impaired in mbo mutants. The blots were hybridized with an actin probe for loading control.
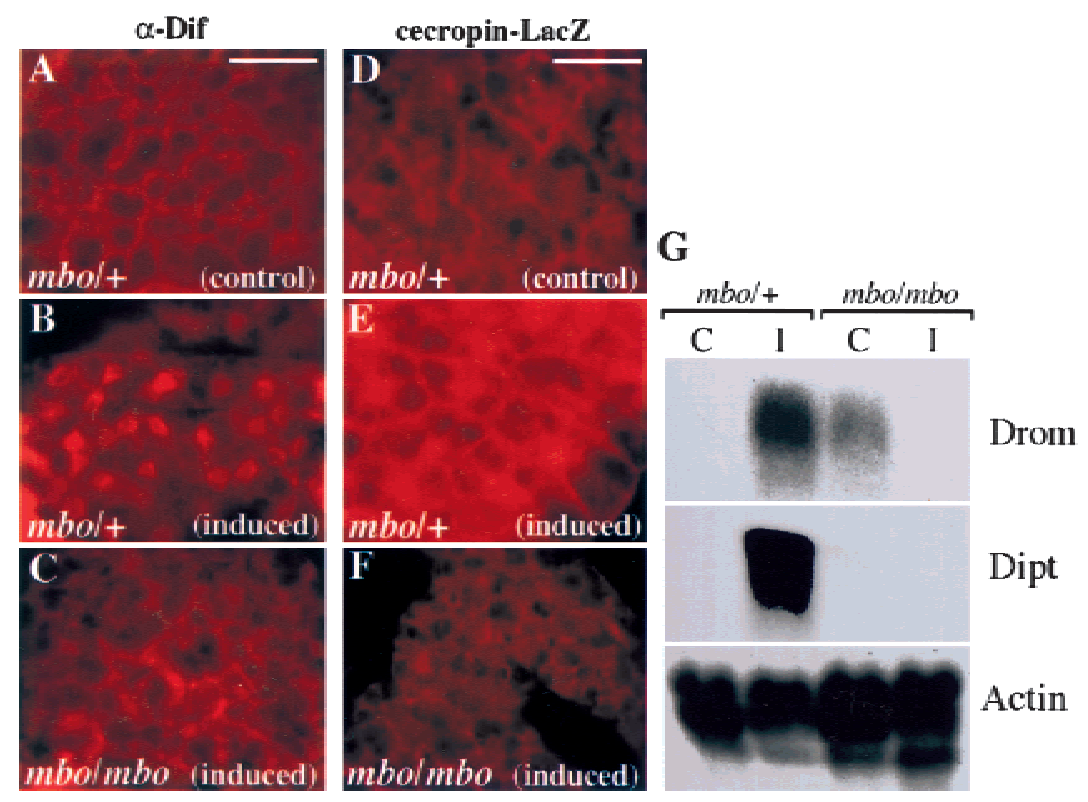
factors require $m b o$ for their nuclear entry and the concomitant activation of their target genes during the larval immune response.

\section{Discussion}

Signal transduction pathways rely on a number of different mechanisms to ensure that active gene regulatory molecules enter the nucleus at the correct time (Kaffman and O'Shea 1999). We have identified an additional requirement of protein translocation upon signaling, at the level of the NPC. The identification of Dnup88 as a cell type-specific nucleoporin selectively required for Rel protein translocation demonstrates distinct requirements for NPC components during different signaling events. It also indicates that the NPC machinery itself contains a gene regulatory potential providing new targets for manipulation and drug design.

\section{Localization and function of Dnup88 and its homologs in the NPC}

The removal of one of the $\sim 100$ different components of each pore can cause structural disturbances and thus affect several transport pathways. For example, mutations in several yeast nucleoporins (Doye and Hurt 1995), and also in Drosophila Nup154 (Gigliotti et al. 1998), cause clustering of NPCs, alter the nuclear envelope structure, and in several cases have been shown to cause accumulation of RNA in the nucleus. In mbo mutants we have not found any impairment of mRNA export or abnormalities in the structure of the nuclear envelope and NPC distribution. Dnup88 is therefore unlikely to be a structural component required for the organization of the NPC, nor is it likely to be involved in RNA export.

The protein import phenotype of mbo mutants appears surprisingly selective. In yeast a subcomplex of nucleoporins is required for general protein import, including the import of reporter proteins carrying the classic NLS (Stoffler et al. 1999). In contrast, Dnup88 is not required for the nuclear localization of a chimeric $\beta$-galactosidase protein bearing the SV40 NLS. Similarly, two Drosophila transcription factors-Grh, bearing a putative bipartite NLS, and Antp, harboring a putative classical NLS - are also nuclear when expressed ectopically in mbo mutants. In the same cells, however, Rel proteins fail to enter the nucleus upon signaling, and the yeast transcription factor GAL4 bearing an unusual NLS remains cytoplasmic. The selective phenotype of $\mathrm{mbo}$ mutants in GAL4 and Rel nuclear accumulation is unlikely to be due to a subtle general defect in protein import that becomes more dramatic on proteins with slow import kinetics. We did not observe any difference in the nuclear accumulation rates of GAL4 and Grh in wildtype larvae and in fat bodies of mbo larvae. GAL4 remained cytoplasmic even $20 \mathrm{hr}$ after its inducible expression. In addition, the nuclear import rate of Dorsal has been directly compared to the import rate of a $\beta$-galactosidase-SV40 T-antigen NLS fusion protein and was found to be very similar both in intact and perforated tissue culture cells (Briggs et al. 1998). These results argue for a direct requirement for Dnup88 in the nuclear localization of a distinct subset of proteins.

Dnup88 shows homology throughout its entire length to the mammalian nuclear pore protein Nup88. The function of human and rat Nup88 remains unknown, but both have been shown to bind to another component of the NPC, CAN/Nup214 (Bastos et al. 1997; Fornerod et al. 1997). Similarly, the fly CAN homolog binds to bacterial Dnup88 fusion proteins in vitro (A. Wickberg and C. Samakorlis, unpubl.), arguing for conservation in their function in nuclear trafficking. Vertebrate CAN is implicated in protein export from the nucleus via its interaction with the exportin CRM1 (Askjaer et al. 1999), and CAN mutant mice also show defects in classical NLS protein import and mRNA export (Deursen et al. 1996). Interestingly, a short segment of the carboxyl terminus in Dorsal has been termed a cytoplasmic anchor, and its deletion results in increased levels of nuclear Dorsal (Rushlow et al. 1989). This segment disrupts a sequence motif with striking similarity to the protein export signal for CRM1, suggesting that the nuclear concentration of Dorsal may also be regulated by protein export. We have not detected any nuclear accumulation of Dorsal in mbo larvae, indicating that the primary function of Dnup88 is not nuclear protein export. We have also analyzed the localization of two Drosophila proteins that are activly exported from the nucleus-Cyclin B (Yang et al. 1998) and MAPK (Ferrigno et al. 1998) —and did not detect any nuclear accumulation for either of these proteins in mbo mutants. In addition, the cytoplasmic accumulation of GAL4 in mbo mutants argues further that Dnup88 is only required for protein import.

\section{Mechanisms of Dnup88-mediated translocation and the definition of its substrates}

The selective requirement for Dnup88 in import of Dorsal and GAL4 suggests that different proteins utilize distinct nucleoporins during their translocation process. Dnup88 is localized at distinct spots on the nuclear envelope, and its vertebrate homologs reside on the cytoplasmic face of the NPC in association with CAN/ Nup214 on the cytoplasmic filaments (Kraemer et al. 1994; Bastos et al. 1997). Visualization of protein import by electron microscopy indicates that cytoplasmic filaments provide the initial binding sites for nuclear import substrates (Panté and Aebi 1996). Because Dnup88 and Dorsal can be coimmunoprecipitated, we propose that Dnup88 may be part of a receptor complex for a distinct class of import substrates.

How, then, is the affinity for this receptor complex defined at the level of its substrate? Because we have not detected any sequence similarity between the Dorsal NLS and the unusual NLS of GAL4, it is possible that the selectivity of Dnup88 lies in the recognition of its cargo proteins together with a distinct importin. The cytoplasmic transport receptor for classical NLS, the importin- $\alpha$ and $-\beta$ complex, is unlikely to be recognized by Mbo, as classic NLS import is not affected in mbo mutants. In- 
terestingly, binding of the GAL4 NLS was observed only by the $\beta$-importin subunit and not by the $\alpha$-importin subunit, which recognizes conventional NLSs such as that of SV40 T antigen (Chan et al. 1998). Although the Dorsal NLS is similar to the classic NLS, it may also require a distinct importin complex in vivo. The in vitro binding affinity of the Dorsal NLS for the importin- $\alpha$ and $-\beta$ complex was found to be about fourfold lower than the affinity of the same complex for the NLS of SV40 T antigen (Briggs et al. 1998). In addition, detailed analysis of the requirements for Dorsal nuclear translocation has revealed that both the presence of its NLS and phosphorylation are necessary for nuclear targeting (Govind et al. 1996; Drier et al. 1999). Thus, the NLS of Dorsal in conjunction with its phosphorylation upon signaling could provide a substrate for a distinct complex of transport factors, which in turn would be recognized by Dnup88 for docking and translocation across the NPC.

\section{Signaling through $M b o$ and the activation of the immune response}

$m b o$ is dynamically expressed and required during distinct developmental processes, including growth of the CNS and imaginal disks, oogenesis, and fusion of the tracheal branches. Furthermore, the selective nuclear import defect of mbo mutants is defined to a subset of larval tissues. In addition to mbo, germ cell-less $(\mathrm{gcm})$, which encodes another Drosophila nuclear envelope protein, shows cell-specific expression and functions in germ-line development (Jongens et al. 1994). Thus, the composition of the nucleocytoplasmic transport machinery is differentially regulated during development, and distinct cells require specific components of the NPC to complete their developmental programs successfully. Because the Dnup88 pathway is selectively required for the import of a distinct subset of nuclear proteins, its differential expression could provide a regulatory function during development by modifying the import capacity of distinct cells. However, it appears unlikely that the mere presence of Dnup88 has an instructive role in development, as we were unable to detect gross developmental defects upon ectopic expression of the gene (A. Uv, unpubl.). The identification of additional transcriptional regulators that require Dnup88 for nuclear entry during tracheal development and oogenesis will help elucidate the gene regulatory capacities of Dnup88 and the nuclear import machinery.

$m b o$ exhibits an intriguing function upon bacterial infection. In mbo mutants the signal transduction cascade leading to Cactus degradation is functional, but the nuclear translocation of Dorsal and Dif is impaired. mbo larvae are also impaired in the activation of several genes encoding antimicrobial peptides, including Drosomycin, Cecropin, and Diptericin. This relatively severe immune deficiency of $m b o$ larvae cannot be solely explained by the lack of Dorsal and Dif translocation, as larvae carrying a deficiency for both dorsal and dif are mainly impaired in the activation of drosomycin and not diptericin (Manfruelli et al. 1999; Meng et al. 1999). Thus, addi- tional transcriptional regulators are expected to use the Dnup88 pathway for nuclear entry. Such a candidate target is Relish, the third identified member of the Drosophila Rel family. relish mutants show a broad defect in the activation of antimicrobial peptides that also includes a block in diptericin and cecropin induction (Hedengren et al. 1999). Thus, the mbo phenotype is consistent with a defect in the nuclear import of all three Rel family members upon an immune response. Given the apparent functional conservation of the insect and mammalian innate immune responses we anticipate that the human mbo homolog may also have a key role in the activation of innate and inflammatory immune responses.

\section{Materials and methods}

Molecular biology

Genomic DNA from the mbo gene was obtained by plasmid rescue in Escherichia coli after cleaving genomic DNA from the 1(3)5043 strain with XbaI. The P1 clone DS00573 was provided by the Berkely Drosophila Genome Project (BDGP). Northern and Western blots, screening of cDNA libraries, and DNA sequencing were done according to Sambrook et al. (1989). mbo cDNAs were isolated from an embryonic cDNA library using a 1.1-kb EcoRI-HindIII fragment (Fig. 1B) as probe. The longest cDNA was sequenced on both strands. The deletions in mbo mutant strains were analyzed on genomic Southern blots probed with DNA fragments deriving from the mbo gene.

\section{Immunostaining and in situ hybridization of embryos and larvae}

Immunostainings of embryos were as described (Samakovlis et al. 1996a). The tracheal lumen-specific antibody mAb 2A12 was used at 1:5, and rabbit anti- $\beta$-galactosidase (Cappel) at 1:1500. Secondary antibodies conjugated to biotin, Cy2, or Cy3 (Jackson Laboratories) were reconstituted as recommended and then used at 1:300. The Dnup88 antisera were prepared by injecting rabbits (Agrisera) with proteins, either containing amino acids 505-702 corresponding to the carboxyl terminus of Dnup88 or amino acids 54-468 from the N-terminal part of Dnup88, fused in frame to the $6 x$ His coding sequence of pRSET C and A (Invitrogen). The antisera were affinity purified on columns of the corresponding His-tagged Dnup88 fusion proteins bound to NiNTA resin and used at 1:100 dilution for Western blots and immunohistochemistry.

Antibody stainings of larval tissues were essentially as described (Patel 1994) except when using the Hdc antibody, which was done according to Weaver and White (1995). The following primary antibodies were used: anti-Dorsal (Gillespie and Wasserman 1994) diluted 1:1000; anti-DIF diluted 1: 300 (Cantera et al. 1999); anti-lamin Dm0 (mAb ADL84) diluted 1:200; anti-GRH (Bray and Kafatos 1991) diluted 1:5; anti-Antp (Condie et al. 1991) diluted 1:50; anti-Hdc (Weaver and White 1995) diluted 1:1; anti-Ubx (White and Wilcox 1984) diluted 1:10; anti-Exd (Aspland and White 1997) diluted 1:10; anti-cyclin B (DSHB) diluted 1:4; anti-phosphorylated ERK (Sigma) diluted 1:500; and anti-GAL4 diluted 1:500 (monoclonal antibody from Santa Cruz Biotechnology). The anti- $\beta$-tubulin antibody used for Western blots at 1:1000 dilution was from Amersham.

Digoxigenin-labeled probes for in situ hybridizations of larval tissues (Lehmann and Tautz 1994) were made by random prim- 
ing the whole mbo cDNA insert or the 841-bp BamHI-ClaI fragment of lacZ.

\section{Analysis of immune response}

Bacterial injections were performed by pricking larvae with a tungsten needle dipped in a concentrated mixture of $E$. coli and Micrococcus luteus. Infected larvae were analyzed after $45 \mathrm{~min}$ for Dorsal and Dif translocation, after $2 \mathrm{hr}$ for antimicrobial peptide expression, and after $30 \mathrm{~min}$ for Cactus degradation.

The Cactus antiserum (Reach et al. 1996) was used at $1 / 1000$ dilution on Western blots. Antibacterial peptide expression was analyzed using anti- $\beta$-galactosidase antibodies to detect $c e c-$ lacZ expression and by Northern blots of total RNA probed with DNA derived from drosomycin (Fehlbaum et al. 1994) and diptericin (Wicker et al. 1990) cDNAs.

\section{Immunoprecipitation}

Immunoprecipitations from embryonic extracts were performed as described in Edwards et al. (1997) except for the lysis buffer [10 mM Tris at pH 8.0, $140 \mathrm{~mm} \mathrm{NaCl}, 1.5 \mathrm{~mm} \mathrm{MgCl} 2,1 \%$ NP-40, protease inhibitor cocktail (Boehringer), $5 \mathrm{~mm}$ pyrophosphate, $10 \mathrm{~mm} \mathrm{NaF}, 10 \mathrm{~mm} \beta$-glycerol phosphate, $5 \mathrm{~mm}$ sodium vanadate].

\section{Electron microscopy}

Wild-type and mbo mutant larvae were prepared for EM as described (Englund et al. 1999) and examined with a Jeol 100 CX electron microscope.

\section{Drosophila strains}

One hundred excision strains from 1(3)5043 were generated as described (Robertson et al. 1988) and balanced either over TM3UbxLacZ or Tm6b. hs-mbo transgenic fly strains were generated by P-element-mediated transformation (Spradling 1986) using the 2514-bp mbo cDNA insert cloned into the StuI and EcoRI sites of pPCaSpeR-hs. Two independent strains with single inserts on the second chromosome were used for rescue of both $m b o-1$ and $m b o-2$ lethality. Other strains used for ectopic gene expression were hs-grh (from S.J. Bray, Dept. of Anatomy, Cambridge, England), hs-hdc (Weaver and White 1995), hs-GAL4 (described on Flybase), UAS-GFPNLSlacZ (Shiga et al. 1996), hs-Antp (Zeng et al. 1993), and cec-lacZ (Petersen et al. 1995). Heat shock-induced protein expression was induced by treatment at $37^{\circ} \mathrm{C}$ for $30 \mathrm{~min}$. Unless stated otherwise, larvae were left to recover for $2 \mathrm{hr}$ before analysis. Germ-line clones were generated as described (Chou et al. 1993). The tracheal fusion marker strains used were Fusion-1, Fusion6, and Terminal-1 (Samakovlis et al. 1996b).

\section{Acknowledgments}

We thank S. Wasserman, S.J. Bray, R. White, M. Scott, Y. Engström, P. Fisher, and S. Hayashi for reagents and fly strains. We also thank T. Jessel, T. Edlund, M. Fornerod, and our colleagues at UCMP for useful discussions and comments on the manuscript. This work was supported by grants from SSF and NFR to C.S. A.U. was a Wenner-Gren postdoctoral fellow.

The publication costs of this article were defrayed in part by payment of page charges. This article must therefore be hereby marked "advertisement" in accordance with 18 USC section 1734 solely to indicate this fact.

\section{References}

Askjaer, P., Bachi, A., Wilm, M., Bischoff, F.R., Weeks, D.L., Ogniewski, V., Ohno, M., Niehrs, C., Kjems, J., Mattaj, I.W., et al. 1999. RanGTP-regulated interactions of CRM1 with nucleoporins and a shuttling DEAD-box helicase. Mol. Cell. Biol. 19: 6276-6285.

Aspland, S.E. and White, R.A. 1997. Nucleocytoplasmic localisation of extradenticle protein is spatially regulated throughout development in Drosophila. Development 124: 741-747.

Bastos, R., Ribas de Pouplana, L.R., Enarson, M., Bodoor, K., and Burke, B. 1997. Nup84, a novel nucleoporin that is associated with CAN/Nup214 on the cytoplasmic face of the nuclear pore complex. J. Cell Biol. 137: 989-1000.

Bray, S.J. and Kafatos, F.C. 1991. Developmental function of Elf-1: An essential transcription factor during embryogenesis in Drosophila. Genes \& Dev. 5: 1672-1683.

Briggs, L.J., Stein, D., Goltz, J., Corrigan, V.C., Efthymiadis, A., Hübner, S., and Jans, D.A. 1998. The cAMP-dependent protein kinase site $\left(\mathrm{Ser}^{312}\right)$ enhances dorsal nuclear import through facilitating nuclear localization sequence/importin interaction. J. Biol. Chem. 273: 22745-22752.

Cantera, R., Roos, E., and Engström, Y. 1999. Dif and Cactus are colocalized in the larval nervous system of Drosophila melanogaster. J. Neurobiol. 38: 16-26.

Chan, C.K., Hubner, S., Hu, W., and Jans, D.A. 1998. Mutual exclusivity of DNA binding and nuclear localization signal recognition by the yeast transcription factor GAL4: Implications for nonviral DNA delivery. Gene Ther. 5: 1204-1212.

Chou, T.B., Noll, E., and Perrimon, N. 1993. Autosomal $\mathrm{P}\left[\mathrm{ovo}^{\mathrm{D} 1}\right]$ dominant female-sterile insertions in Drosophila and their use in generating germ-line chimeras. Development 119: 1359-1369.

Condie, J.M., Mustard, J.A., and Brower, D. 1991. Generation of anti-Antennapedia monoclonal antibodies and Antennapedia protein expression in imaginal discs. Dros. Inf. Serv. 70: $52-54$.

Doye, V. and Hurt, E.C. 1995. Genetic approaches to nuclear pore structure and function. Trends Genet. 11: 235-241.

Drier, E.A., Huang, L.H., and Steward, R. 1999. Nuclear import of the Drosophila Rel protein Dorsal is regulated by phosphorylation. Genes \& Dev. 13: 556-568.

Edwards, D.N., Towb, P., and Wasserman, S.A. 1997. An activity-dependent network of interactions links the Rel protein Dorsal with its cytoplasmic regulators. Development 124: 3855-3864.

Englund, C., Uv, A.E., Cantera, R., Mathies, L.D., Krasnow, M.A., and Samakovlis, C. 1999. Adrift, a novel bnl-induced Drosophila gene, required for tracheal pathfinding into the CNS. Development 126: 1505-1514.

Fehlbaum, P., Bulet, P., Michaut, L., Lagueux, M., Broekaert, W.F., Hetru, C., and Hoffmann, J.A. 1994. Insect immunity. Septic injury of Drosophila induces the synthesis of a potent antifungal peptide with sequence homology to plant antifungal peptides. J. Biol. Chem. 269: 33159-33163.

Ferrigno, P., Posas, F., Koepp, D., Saito, H., and Silver, P.A. 1998. Regulated nucleo/cytoplasmic exchange of HOG1 MAPK requires the importin beta homologs NMD5 and XPO1. EMBO J. 17: 5606-5614.

Fornerod, M., van Deursen, J., van Baal, S., Reynolds, A., Davis, D., Murti, K.G., Fransen, J., and Grosveld, G. 1997. The human homolgue of yeast CRM1 is in a dynamic subcomplex with CAN/Nup214 and a novel nuclear pore component Nup88. EMBO I. 16: 807-816.

Gabay, L., Seger, R., and Shilo, B.Z. 1997. In situ activation pattern of Drosophila EGF receptor pathway during devel- 
opment. Science 277: 1103-1106.

Gigliotti, S., Callaini, G., Andone, S., Riparbelli, M.G., PernasAlonso, R., Hoffmann, G., Graziani, F., and Malva, C. 1998. Nup154, a new Drosophila gene essential for male and female gametogenesis is related to the nup 155 vertebrate nucleoporin gene. J. Cell Biol. 142: 1195-1207.

Gillespie, S.H. and Wasserman, S.A. 1994. Dorsal, a Drosophila rel-like protein, is phosphorylated upon activation of the transmembrane protein toll. Mol. Cell. Biol. 14: 3559-3568.

Govind, S., Drier, E., Huang, L.H., and Steward, R. 1996. Regulated nuclear import of the Drosophila rel protein dorsal: Structure-function analysis. Mol. Cell Biol. 16: 1103-1114.

Görlich, D. and Kutay, U. 1999. Transport between the cell nucleus and the cytoplasm. Annu. Rev. Cell Dev. Biol. 15: 607-660.

Hedengren, M., Asling, B., Dushay, M.S., Ando, I., Ekengren, S., Wihlborg, M., and Hultmark, D. 1999. Relish, a central factor in the control of humoral but not cellular immunity in Drosophila. Mol. Cell 4: 827-837.

Hoffmann, J.A., Kafatos, F.C., Janeway, C.A., and Ezekowitz, R.A. 1999. Phylogenetic perspectives in innate immunity. Science 284: 1313-1318.

Ip, Y.T., Reach, M., Engström, Y., Kadalayil, L., Cai, H., Gonzalez-Crespo, S., Tatei, K., and Levine, M. 1993. Dif, a dorsalrelated gene that mediates an immune response in Drosophila. Cell 75: 753-763.

Jongens, T.A., Ackerman, L.D., Swedlow, J.R., Jan, L.Y., and Jan, Y.N. 1994. Germ cell-less encodes a cell type-specific nuclear pore-associated protein and functions early in the germ-cell specification pathway of Drosophila. Genes \& Dev. 8: 2123-2136.

Kaffman, A. and O'Shea, E.K. 1999. Regulation of nuclear localization: A key to a door. Annu. Rev. Cell Dev. Biol. 15: 291339.

Kraemer, D., Wozniak, R.W., Blobel, G., and Radu, A. 1994. The human CAN protein, a putative oncogene product associated with myeloid leukemogenesis, is a nuclear pore complex protein that faces the cytoplasm. Proc. Natl. Acad. Sci. 91: 1519-1523.

Lehmann, R. and Tautz, D. 1994. In situ hybridization to RNA. In Drosophila melanogaster: Practical uses in cell and molecular biology (ed. S.B. Goldstein and E.A. Fyrberg), pp. 575598. Academic Press, Cambridge, MA.

Lemaitre, B., Nicolas, E., Michaut, L., Reichhart, J.M., and Hoffmann, J.A. 1996. The dorsoventral regulatory gene cassette spatzle/Toll/cactus controls the potent antifungal response in Drosophila adults. Cell 86: 973-983.

Manfruelli, P., Reichhart, J.M., Steward, R., Hoffmann, J.A., and Lemaitre, B. 1999. A mosaic analysis in Drosophila fat body cells of the control of antimicrobial peptide genes by the Rel proteins Dorsal and DIF. EMBO I. 18: 3380-3391.

Mann, R.S. and Abu-Shaar, M. 1996. Nuclear import of the homeodomain protein extradenticle in response to $\mathrm{Wg}$ and Dpp signalling. Nature 383: 630-633.

Manning, G. and Krasnow, M.A. 1993. Development of the Drosophila tracheal system. In The development of Drosophila melanogaster (ed. M.A. Bate), pp. 609-685. Cold Spring Harbor Laboratory Press, Cold Spring Harbor, NY.

Meng, X., Khanuja, B.S. and Ip, Y.T. 1999. Toll receptor-mediated Drosophila immune response requires Dif, an NF-кB factor. Genes \& Dev. 13: 792-797.

Mercurio, F. and Manning, A.M. 1999. Multiple signals converging on NF-kappaB. Curr. Opin. Cell Biol. 11: 226-232.

Morisato, D. and Anderson, K.V. 1995. Signaling pathways that establish the dorsal-ventral pattern of the Drosophila embryo. Annu. Rev. Genet. 29: 371-399.
Nicolas, E., Reichhart, J.M., Hoffmann, J.A., and Lemaitre, B. 1998. In vivo regulation of the IkappaB homologue cactus during the immune response of Drosophila. I. Biol. Chem. 273: 10463-10469.

Panté, N. and Aebi, U. 1996. Sequential binding of import ligands to distinct nucleopore regions during their nuclear import. Science 273: 1729-1732.

Patel, N.H. 1994. Imaging neuronal subsets and other cell types in whole-mount Drosophila embryos and larvae using antibody probes. In Drosophila melanogaster: Practical uses in cell and molecular biology (ed. S.B. Goldstein and E.A. Fyrberg), pp. 45-487. Academic Press, Cambridge, MA.

Petersen, U.M., Björklund, G., Ip, Y.T., and Engström, Y. 1995. The dorsal-related immunity factor, Dif, is a sequence specific trans-activator of Drosophila Cecropin gene expression. EMBO T. 14: 3146-3158.

Reach, M., Galindo, R.L., Towb, P., Allen, J.L., Karin, M., and Wasserman, S.A. 1996. A gradient of cactus protein degradation establises dorsoventral polarity in the Drosophila embryo. Dev. Biol. 180: 353-364.

Robertson, H.M., Preston, C.R., Phillis, R.W., Johnson-Schlitz, D.M., Benz, W.K., and Engels, W.R. 1988. A stable genomic source of $\mathrm{P}$ element transposase in Drosophila melanogaster. Genetics 118: 461-470.

Rushlow, C.A., Han, K., Manley, J.L., and Levine, M. 1989. The graded distribution of the dorsal morphogen is initiated by selective nuclear transport in Drosophila. Cell 59: 11651177.

Saavedra, C.A., Hammell, C.M., Heath, C.V., and Cole, C.N. 1997. Yeast heat shock mRNAs are exported through a distinct pathway defined by Riplp. Genes \& Dev. 11: 28452856.

Samakovlis, C., Hacohen, N., Manning, G., Sutherland, D., Guillemin, K., and Krasnow, M.A. 1996a. Development of the Drosophila tracheal system occurs by a series of morphologically distinct but genetically coupled branching events. Development 122: 1395-1407.

Samakovlis, C., Manning, G., Steneberg, P., Hacohen, N., Cantera, R., and Krasnow, M.A. 1996b. Genetic control of epithelial tube fusion during Drosophila tracheal development. Development 122: 3531-3536.

Sambrook, J., Fritsch, E.F., and Maniatis, T. 1989. Molecular cloning: A laboratory manual, 2nd ed. Cold Spring Harbor Laboratory Press, Cold Spring Harbor, N.Y.

Schneider, D.S., Hudson, K.L., Lin, T.Y., and Anderson, K.V. 1991. Dominant and recessive mutations define functional domains of Toll, a transmembrane protein required for dorsal-ventral polarity in the Drosophila embryo. Genes \& Dev. 5: 797-807.

Shah, S. and Forbes, D.J. 1998. Separate nuclear import pathways converge on the nucleoporin Nup153 and can be dissected with dominant-negative inhibitors. Curr. Biol. 8: 1376-1386.

Shiga, Y., Tanaka-Matakatsu, M., and Hayashi, S. 1996. A nuclear GFP/ beta-galactosidase fusion protein as a marker for morphogenesis in living Drosophila. Dev. Growth Differ. 38: 99-106.

Silver, P.A., Keegan, L.P., and Ptashine, M. 1984. Amino terminus of the yeast GAL4 gene product is sufficient for nuclear localization. Proc. Natl. Acad. Sci. 81: 5951-5955.

Spradling, A.C. 1986. P element-mediated transformation. In Drosophila: A practical approach (ed. D.B. Roberts), pp. 175198. Oxford University Press, Oxford, UK.

Stoffler, D., Fahrenkrog, B., and Aebi, U. 1999. The nuclear pore complex: From molecular architecture to functional dynamics. Curr. Opin. Cell Biol. 11: 391-401. 
van Deursen, J., Boer, J., Kasper, L., and Grosveld, G. 1996. G2 arrest and impaired nucleocytoplasmic transport in mouse embryos lacking the proto-oncogene CAN/Nup214. EMBO J. 15: 5574-5583.

Weaver, T. and White, R. 1995. Headcase, an imaginal specific gene requred for adult morphogenesis in Drosophila melanogaster. Development 121: 4149-4160.

White, R.A.H. and Wilcox, M.E. 1984. Protein products of the Bithorax complex in Drosophila. Cell 39: 163-171.

Wicker, C., Reichhart, J.M., Hoffmann, D., Hultmark, D., Samakovlis, C., and Hoffmann, J.A. 1990. Insect immunity. Characterization of a Drosophila cDNA encoding a novel member of the diptericin family of immune peptides. J. Biol. Chem. 265: 22493-22498.

Yang, J., Bardes, E.S., Moore, J.D., Brennan, J., Powers, M.A., and Kornbluth, S. 1998. Control of cyclin B1 localization through regulated binding of the nuclear export factor CRM1. Genes \& Dev. 12: 2131-2143.

Zeng, W., Andrew, D.J., Mathies, L.D., Horner, M.A., and Scott, M.P. 1993. Ectopic expression and function of the Antp and Scr homeotic genes: The $\mathrm{N}$ terminus of the homeodomain is critical to functional specificity. Development 118: 339352. 


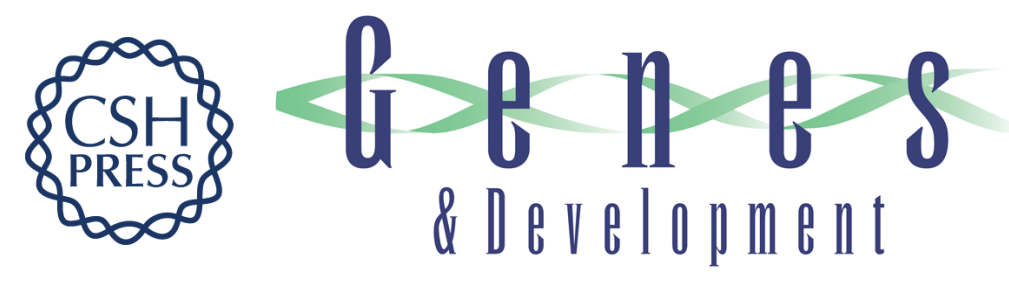

\section{members only encodes a Drosophila nucleoporin required for Rel protein import and immune response activation}

Anne E. Uv, Peggy Roth, Nikos Xylourgidis, et al.

Genes Dev. 2000, 14:

Access the most recent version at doi:10.1101/gad.14.15.1945

References

This article cites 52 articles, 33 of which can be accessed free at: http://genesdev.cshlp.org/content/14/15/1945.full.html\#ref-list-1

License

Email Alerting

Receive free email alerts when new articles cite this article - sign up in the box at the top Service right corner of the article or click here.

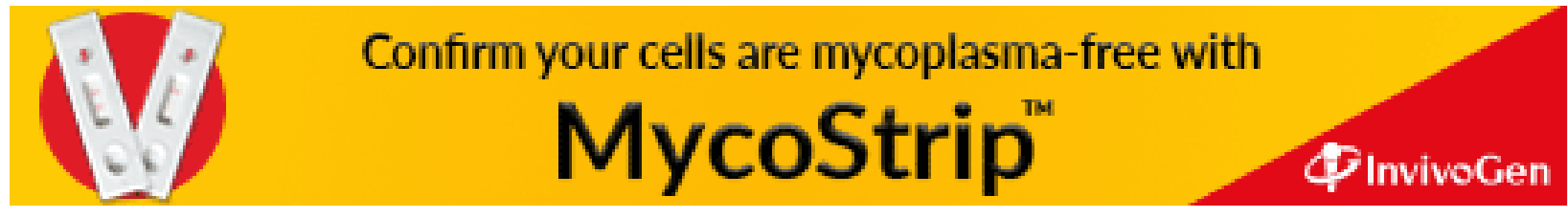

